\title{
Clinical Application of Miniature Peroneal Perforation Flap for Free Grafting In Soft Fibers of Hand, Foot and Skin
}

\author{
Wu Zhilin, Chen Changsong, Zhang Jie, Chen Yang, Wu Chengbin, Li Pehua, Li Lei
}

Armed Police Zhejiang Provincial Corps Hangzhou Hospital

\begin{abstract}
Objective: To study the clinical application and effect of free transplantation of miniature peroneal perforation flap in soft and tissue defects of hand, foot and skin. Method: 28 patients with hand, foot, skin and soft tissue defects who were treated in hospital from May 2015 to May 2016 were selected as the subjects. The patients were randomly divided into group A as experimental group and group B as control group. Two groups of patients with treatment site microcirculation, postoperative recovery and sensory score were compared. Results: The microcirculation indexes of group A were significantly better than those of group $\mathrm{B}(\mathrm{P}<0.05)$. The rate of recovery in group A was $92.86 \%$ and rate of recovery in group B was $71.43 \%$, after treatment recovery in group A is significantly better than group $\mathrm{B}(\mathrm{P}<0.05)$. Before and after treatment, the sensory scores of the two groups were not statistically significant $(\mathrm{P}>0.05)$. The sensory score of group A was significantly higher than that of group B $(\mathrm{P}<0.05)$. Conclusion: The microperitoneal perforation flap dissection has a good clinical effect, which can effectively improve the postoperative recovery of patients with soft tissue defects of hand, foot and skin, improve the microcirculation index of the treatment site and improve the sensory score of the treatment site, should be widely used in clinical treatment.
\end{abstract}

Keywords: miniature peroneal perforation flap free graft; hand, foot and skin; soft tissue defect

\section{Introduction}

Hand and foot skin and soft tissue defects are common types of diseases in clinical surgery, the current clinical treatment, the main way to repair the flap for treatment, and achieved good clinical treatment. However, depending on the choice of flap, its effect on the patient's surgery will also have different effects ${ }^{[1]}$. Based on this study, 28 patients with soft and tissue defects of hand, foot and skin were selected as the research object. The treatment of microperitoneal perforation flap was performed and the treatment was achieved. The results were reported as follows.

\section{Materials and methods}

\subsection{General information}

In this study, 28 patients with soft, tissue and soft tissue defects who were treated in hospital from May 2015 to May 2016 were selected as subjects. After the patients signed the informed consent form of the hospital ethics committee, the clinical study was conducted. When the patient was admitted, the patient's admission number was recorded and counted. At the same time, the random number table was divided into A and B groups according to the patient's admission number. Group A was used as the experimental group and group B as the control group. Among them, A group of 14

This is an Open Access article distributed under the terms of the Creative Commons Attribution-Non Commercial 4.0 International License (http://creativecommons.org/ licenses/by-nc/4.0/), permitting all non-commercial use, distribution, and reproduction in any medium, provided the original work is properly cited. 
cases, 9 males and 5 females, aged 20 years to 56 years, mean age $(35.71 \pm 10.89)$ years; defect area of $2.86 \mathrm{~cm} \times$ $5.21 \mathrm{~cm} \sim 4.02 \mathrm{~cm} \times 11.18 \mathrm{~cm}$. There were 14 cases, 7 males and 7 females, aged 22 to 55 years old, with an average age of $36.84 \pm 10.26$ years. The defect area was $3.03 \mathrm{~cm} \times 5.14 \mathrm{~cm} \sim 3.97 \mathrm{~cm} \times 10.84 \mathrm{~cm}$. All patients included 5 cases of dorsal foot defects, 4 cases of hand dorsal defects, 3 cases of thumb dorsal defect and 2 cases of finger defects. According to the patient's hand, foot and skin soft tissue defects in the statistics, including 25 cases of crush injury, 21 cases of avulsion, 16 cases of crush injury and 8 cases of explosive injury. All patients with hand, foot and wound were infected with varying degrees, and wound with tendon exposed. For the study of group A and B patients with basic data between groups of statistical treatment, $\mathrm{P}>0.05$, no statistical differences, comparable.

\subsection{Method}

A group of patients with microperitoneal perforation flap free graft surgery for treatment, surgical methods are as follows: (1) Preoperative preparation: Preoperative prescriptions for patients before surgery, and patients with vascular ultrasound Doppler (2) The patient to take the lateral position, and its skin and soft tissue defect area debridement treatment, and according to the shape of the treatment site and size, in the patient's lateral leg area, the flap was designed along the axis of the peroneal artery; (3) The flap design area of the leading edge of the skin incision, and in the deep fascia free flap, separated from the peroneal artery after the perforation can be 1 to 2 peroneal artery perforation (4) After the ligation and cut off the fibular artery, according to the size of the defective surface of the patient to cut the appropriate length of the vascular pedicle, and the use of the skin, the use of the skin and the fibula branch, (5) After repair, the wound was sutured and the patient was treated with conventional anti-infective therapy. Group B patients with traditional pedicled abdominal flap transfer to repair the skin and soft tissue defects.

\subsection{Observe indicators}

The blood perfusion volume, erythrocyte velocity, white microembolization, blood flow integral and haematotic state integral were measured and compared with the two groups of patients after treatment. The clinical indexes were compared between the two groups after treatment. Secondly, the postoperative recovery was compared between the two groups, and the recovery was based on the patient's Gartland-Werley wrist function score and the foot Maryland scoring system, which was divided into excellent, good and poor according to the patient's score. Finally, the use of hospital-made sense of functional score on the patient's damaged parts score, full score is 10 points.

\subsection{Statistical processing}

The measurement and statistical data in this study were calculated using SPSS19.0 statistical software, and the statistical data was expressed by (\%), and the data was checked by using $\left(\mathrm{x}^{2}\right)$. In addition, the count data in this study Adoption rate $(\overline{\mathbf{z}} \pm \mathrm{s})$, use ( $\mathrm{t})$ to verify the data. $\mathrm{P}<0.05$ indicates that the difference was statistically significant.

\section{Results}

\subsection{Comparison of the two groups of patients with microcirculation indicators BT can quantify $\beta$ wave of traditional EEG}

The results showed that there was significant difference between group A and group B $(\mathrm{P}<0.05)$, and the difference was statistically significant $(\mathrm{P}<0.05)$. 


\subsection{Comparison of postoperative recovery of the two groups of patients}

The results showed that the A and B patients after treatment, A group of patients with excellent recovery rate of $92.86 \%$, B group of patients with excellent recovery rate of $71.43 \%$, compared with the two groups of patients, A group of patients

with postoperative recovery significantly better than group $\mathrm{B}$, the difference was statistically significant $(\mathrm{P}<0.05)$, see Table 2. Patient treatment before and after the figure shown in Figure 1.

Table 1 Comparison of the two groups of microcirculation indicators $\left(\overline{\boldsymbol{x}}_{ \pm \mathrm{s}}\right.$, points)

\begin{tabular}{ccccccc}
\hline Group & Case & $\begin{array}{c}\text { Blood perfusion } \\
(\mathbf{m L} / \mathbf{s})\end{array}$ & $\begin{array}{c}\text { Erythrocyte flow } \\
\text { rate }(\mathbf{u m} / \mathbf{s})\end{array}$ & $\begin{array}{c}\text { White } \\
\text { microcapsules }(\%)\end{array}$ & $\begin{array}{c}\text { Blood flow integral } \\
\text { state integral }\end{array}$ \\
\hline Group B & 14 & $13.27 \pm 1.36$ & $914.26 \pm 113.72$ & $1.68 \pm 0.22$ & $1.45 \pm 0.11$ & $1.39 \pm 0.13$ \\
t & & 6.821 & 8.643 & 6.031 & 6.256 & 6.143 \\
P & 0.031 & 0.009 & 0.042 & 0.039 & 0.040 \\
\hline
\end{tabular}

Table 2 Comparison of postoperative recovery in both groups [n (\%)]

\begin{tabular}{cccccc}
\hline Group & Case & Excellent & Good & Poor & Excellent rate \\
\hline Group A & 14 & $10(74.43)$ & $3(21.43)$ & $1(7.14)$ & $13(92.86)$ \\
Group B & 14 & $4(28.57)$ & $6(42.86)$ & $4(28.57)$ & $10(71.43)$ \\
x2 & & 11.424 & 4.386 & 6.047 & 6.047 \\
P & & 0.001 & 0.036 & 0.014 & 0.014 \\
\hline
\end{tabular}

\subsection{Comparison of the two groups before and after treatment of the sensory score}

There was no significant difference in sensory score between the two groups ( $\mathrm{P}>0.05)$. The sensory score of group A was significantly higher than that of group $B(P>0.05)$. The sensory score of group A was significantly higher than that of group B statistically significant $(\mathrm{P}<0.05)$, see Table 3 .
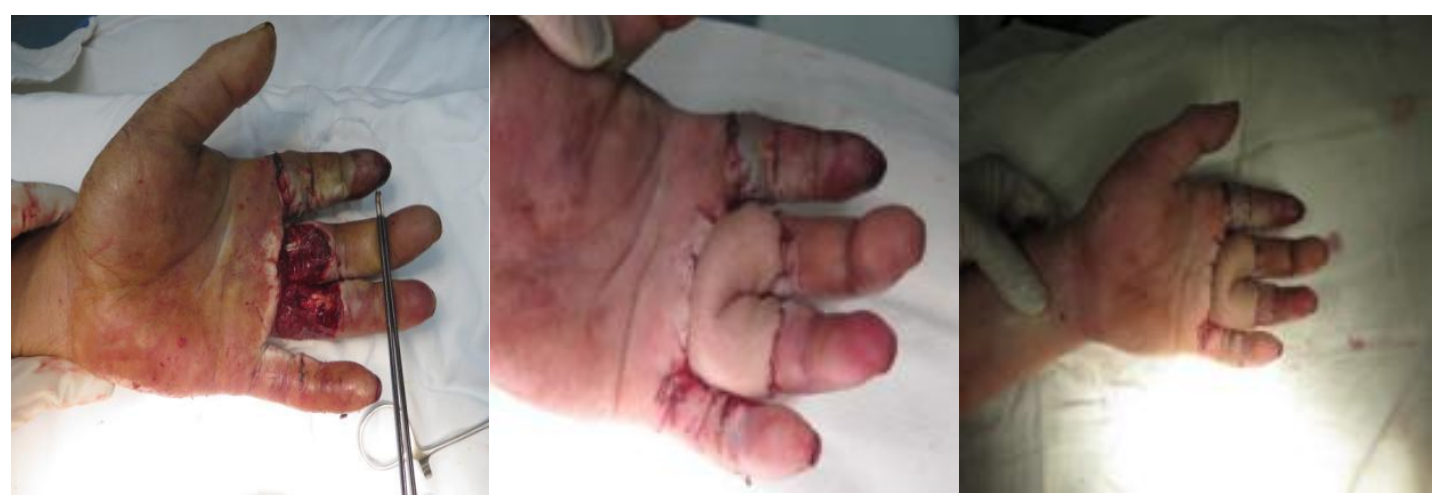

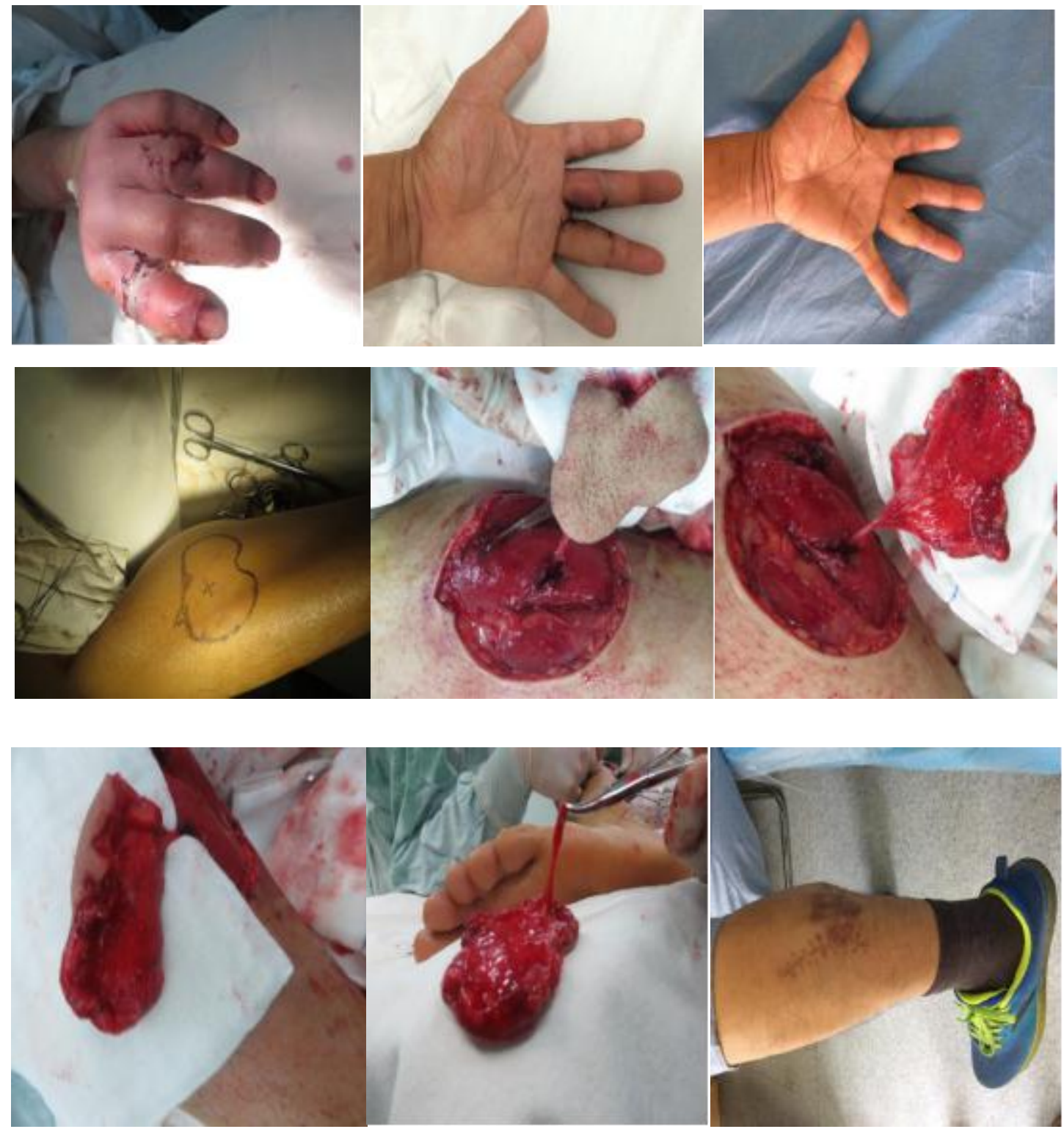

Figure 1 patient before and after treatment

Table 3 Comparison of sensory scores before and after treatment in both groups ( $\underline{\underline{x}} \pm \mathrm{s}$, points)

\begin{tabular}{cccc}
\hline Group & Case & Before treatment & After treatment \\
\hline Group A & 14 & $2.13 \pm 1.17$ & $7.18 \pm 1.86$ \\
Group B & 14 & $2.26 \pm 1.09$ & $5.44 \pm 2.03$ \\
$\mathrm{t}$ & & 1.334 & 6.548 \\
$\mathrm{P}$ & & 0.248 & 0.033 \\
\hline
\end{tabular}

\section{Discussion}

Hand and foot skin and soft tissue defects will not only affect the appearance of beauty, but also affect the function of 
the hand and foot parts of the patient's daily work and life had a greater impact ${ }^{[2]}$. Clinical experience shows that flap repair as the current treatment of skin and soft tissue defects in the main way, according to the choice of flap different location, the resulting clinical treatment effect there are some differences ${ }^{[3]}$. Some researchers have found that the perforation of the perforator flap, which is selected from the free graft of the miniature peroneal perforation flap, is not only convenient for anatomical posture, but does not need to flip the limb of the patient, but also has a relatively fixed vascular anatomical location, The length of up to $9 \mathrm{~cm}$ or more, less than the damage caused by the supply area is relatively small ${ }^{[4]}$. Especially in the clinical treatment of soft tissue defects of hand, foot and skin, based on its relatively small defect area, so the area can be directly sutured, and the site of the flap is relatively thin, to avoid the appearance of patients after the appearance of bloated, etc. High aesthetics.

In the implementation of micro-peroneal perforation flap free graft surgery in the process, should be based on the patient's defective parts and individual differences, first of its conventional Doppler ultrasound vascular detection, the patient's area for a reasonable positioning, The patient was then treated by debridement and the appropriate length of the vessel was chosen ${ }^{[5]}$. At the same time, should be based on the patient's different needs of the affected area, the flap for a reasonable design, the area is usually greater than the defect surface of $3 \mathrm{~mm}$, and the vascular pedicle flap in the process of suturing cannot be too tight, to avoid oppression and vascular crisis ${ }^{[6]}$. Some researchers believe that micro-peroneal perforation flap free graft surgery can effectively improve the function of patients with damaged parts and sensory state, and the supply of flap blood is effectively protected for the recovery of patients had a positive impact [7].

The results of this study show that the microcirculation indexes of patients in group A were significantly better than those in group $\mathrm{B}(\mathrm{P}<0.05)$, which indicated that the microfraction of microperitoneal perforation flap could effectively promote the improvement of microcirculation $(\mathrm{P}<0.05)$. The rate of recovery was $92.86 \%$ in group $\mathrm{A}$ and $71.43 \%$ in group B. The postoperative recovery of group A was significantly better than that of group $\mathrm{B}(\mathrm{P}<0.05)$, indicating that the implementation of miniature peroneal perforation flap free grafting is not only conducive to improving the clinical treatment effect, but also conducive to patients with postoperative recovery. There was no significant difference in sensory score between the two groups before treatment $(\mathrm{P}>0.05)$. After treatment, the sensory score of group A was significantly higher than that of group $\mathrm{B}(\mathrm{P}<0.05)$.

In summary, miniature peroneal perforation flap free graft can effectively achieve the clinical treatment of patients with soft tissue defects, which can not only improve the patient's treatment site of microcirculation indicators, but also can promote the patient's postoperative recovery effect Enhance, and improve the treatment of the sensory score, should be widely used in clinical treatment.

\section{Reference}

1. Li Wen Ping, Wu Duo Qing, Huang You Hua, et al. Closed Negative Pressure Drainage Technique Combined with Peroneal Artery Perforation Flap to Repair Skin and Soft Tissue Defects of the Ankle [J]. Chinese Journal of Reparative and Reconstructive Surgery, 2012 (4).

2. Pan Jia Dong, Wang Xin, Mei Jin, et al. Repair of Soft and Tissue Defects of the Hand and Foot Skin with Free Sural Carpal Perforation Flap [J]. Chinese Journal of Microsurgery, 2012,35 (2).

3. Jiang Chang Qing, Meng Fan Bin, Zhang Jian, et al. Repair of Hand and Foot Skin Defects by Single Transplantation of Single Perforation Microfilament Flap [J]. Chinese Journal of Microsurgery, 2012,35 (2).

4. Li Peng, Ou Zhi Ping, Xie Pei Jun, et al. Perforation of Flap of Percutaneous Perforation Flap for Repair of 30 Cases of Skin and Soft Tissue Defects [J]. Chinese Journal of Medical Science, 2014 (30): 38-39.

5. Yang Guang, Zhang Wei Zhong, Li Li Sen, et al. Application of Free Peroneal Perforation Flap in the Repair of Skin Defects of Hand and Foot [J]. Practical Journal of Hand Surgery, 2016,30 (1). 
6. Zhi Feng, Wang Long Hu, Liang Gao Feng, et al. Application of Free Peroneal Perforation Flap in the Repair of Hand and Foot Soft Tissue Defects in 16 Cases [J]. Chinese Journal of Microsurgery, 2012,35 (5): 411-413.

7. Chen Gui Quan, Chen Wei Ming, Huang Bin, et al. The Clinical Effect of Free Grafting of the Superficial Perforated Flap Pedicled on the Repair of Foot Skin and Soft Tissue Defects [J]. Chinese Medical Engineering, 2014 (1): 171-171. 